\title{
CONTEMPORARY NEEDS OF MEDIA LEARNING MATERIALS FOR FUTURE Z-ENGINEERS
}

\author{
Zoja Veide \\ Riga Technical University, Department of Computer Aided Engineering Graphics, Latvia \\ Veronika Strozheva \\ Riga Technical University, Department of Computer Aided Engineering Graphics, Latvia
}

\begin{abstract}
Modern students are digital natives: from an early age, they are used the Internet, social networks and mobile systems. Due to the specific brain structure of Generation $\mathrm{Z}$ students, the use of traditional teaching tools makes the learning process not effective. Also, an insufficient number of lecture hours in curricula requires from students more independent work. This article presents the experience of creating interactive teaching materials designed to study and master the skills of graphical engineering subjects. Educators of technical universities from five countries took part in the development of the material. These interactive teaching tools are created with the aim of improving the quality of engineering education, the rapid and effective presentation of educational material, which will contribute to the understanding of difficult topics.
\end{abstract}

Keywords: DIAD-tools, Engineering Graphics, Generation Z, interactive teaching tools.

\section{Introduction}

The modern era is a period of highly developed information technology. New technologies are changing all areas of our lives, including education. The current generation of students is actively using innovative Internet technologies. Generation $\mathrm{Z}$ from an early age actively uses computers, camcorders, mobile phones and other tools of the digital era. Contemporary students first began to play computer games, and only then began to learn to read and write, or these processes occurred in parallel. Due to the huge amount of interaction with the digital environment, thinking processes and information processing process of modern students takes place in a different way in comparison with their predecessors. They need to receive information quickly. They love the parallel process and multitasking. They prefer graphics and video rather than printed text and the learning process by way of the game.

The rapid development of information technology and the search for new educational methods of generation $\mathrm{Z}$ have contributed to research in the field of educational technology. Educational computer games are being developed that consider the specific aspects of teaching engineering graphics and contribute to 
the development of spatial abilities (Jurane, 2013). The article (Branoff \& Dobelis, 2012) considers a method for measuring literacy in the field of engineering graphics using modern 3D parametric modelling CAD software. Using spatial comprehension and interpretation skills of the assembly drawing, students had to model as many individual parts as possible over a limited period.

Studies show that video can be an effective teaching tool (Weinberg \& Thomas, 2018). A review of the studies revealed several advantages, including an increase in students' interest in learning, academic performance on tests, and an improvement in the perception of educational material (Kay, 2012). Video material is an important pedagogical tool in the process of education of the 21st century and there are more and more studies in which the best methods are identified to make the learning process using video more successful (Guo, Kim, \& Rubin, 2014), (Kim et al., 2014).

The article describes educational specific needs of Generation Z students and the results of the project "Development of Interactive and Animated Drawing Teaching Tools" DIAD-tools. In the development of the project, the specific needs of students in modern teaching materials were taken into account. The aim of the project is to create learning tools for teaching engineering graphical subjects for modern students of vocational schools, colleges and universities. These interactive teaching tools will enable to better master the teaching materials and increase future z-engineers motivation to study as well as help students memorize the information and put it into practice. As training tools, video materials on certain topics of engineering graphics and descriptive geometry were created.

\section{Needs of Generation Z}

Generation $\mathrm{Z}$ is the first generation born in the world of global technology. They grew up in the world of the global Internet, smartphones and videos, gaming devices and social networks. The use of modern technologies (such as GPS, Bluetooth, etc.), which have traditionally been used only in professional fields, is natural for them. Electronic technology has supplanted spatial performance. Therefore, students often have difficulties with abstract concepts (Cilliers, 2017). Students rely on online resources rather than notes, and they expect an entertaining component from lectures. Enrolling at universities, they expect to get into an environment like the virtual world. The generation does not memorize information well but knows for sure where it can be quickly found and is always ready to consult in social networks. This indicates the need for rapid information receiving, visual forms of training. The "brain of generation" is adapted to complex visual images, which makes visual forms of learning particularly effective. However, Generation $\mathrm{Z}$ has clip thinking and is not ready to perceive new information for a long time. This should be considered when developing 
training videos. It should also in mind that a representative of this generation was born and raised in a stable time. At first, his parents decided everything for him, now he expects the same from teachers. Therefore, students have difficulties with independent work. The goal of the generation training is to move from traditional teaching methods to a learning strategy designed for Z-students.

\section{DIAD-tools Description of the project}

The DIAD-tools project brought together members of eight organizations from five European countries - Latvia, Lithuania, Poland, Slovakia and Estonia. The duration of this project is thirty months, the start of the project is October 2017. The target group of the project included the following categories of people: students of vocational schools, teachers of vocational education, students of higher schools and colleges, lecturers of higher schools and colleges, as well as scientists and specialists in the field of Technical Graphics, Descriptive Geometry, Engineering Computer Graphics, Civil Engineering, Mechanical Engineering.

The partners of the DIAD-tools project were picked in accordance with their work experience, competencies, skills necessary for the implementation of the project. The following organizations participated in the project: Public Institution Vilnius Builders Training Centre - project applicant, coordinator; Slovak University of Technology in Bratislava - the creation of educational materials; Ida-Virumaa Vocational Education Centre - dissemination and evaluation of activities; Vytautas Magnus University. Agriculture Academy - analysis of methodological materials and creation of educational materials, Lithuanian Society of Engineering Graphics and Geometry - monitoring of progress, quality and achievement of project activities; Riga Technical University - creation of educational materials; Panevėžio kolegija / University of Applied Sciences preparing a methodology for testing educational materials of a project, processing test results and developing recommendations for improving educational materials; Silesian University of Technology - the creation of teaching materials.

The goal of the project is the creation of interactive and animated teaching tools for studying certain topics of engineering graphics and descriptive geometry. Developed teaching tools have to motivate students to learn and facilitate comprehension of teaching materials. Project participants had the opportunity to share their experience in the field of teaching. When developing training materials, the symbols and drawing elements were in accordance with ISO international standards. Universities experts from four countries of the European Union working on the creation of teaching materials developed four chapters of interactive teaching tools: 
Veide \& Strozheva, 2020. Contemporary Needs of Media Learning Materials for Future Z-Engineers

1. Execution of drawings. Geometric drawing.

2. Basics of projection drawing. Views. Sections. Sectional views.

3. Joints of parts. Working drawings of parts.

4. Construction drawings.

Materials were created in accordance with the following steps:

1. analysis and description of the content of topics (English version);

2. collecting information, structuring content and creating materials (English version);

3. Posting a trial version of materials on the project website (English version);

4. translation of the textual content of educational materials from English into Lithuanian, Estonian, Latvian, Polish, Slovak;

5. posting translated teaching materials on the project website and preparing for testing;

6. testing a trial version of training materials in partner countries;

7. processing of test results and development of recommendations for improving educational materials;

8. Improving materials, creating the final version and publishing the improved version of the project training materials on the project website.

\section{Needs Analysis Study}

At the stage of developing the content of educational materials, the Needs Analysis Study was conducted. The survey was organized in five countries participating in the project. The purpose of this survey was to study the methodology of teaching graphic subjects in the countries of the project partners, the relevance of the chapters of educational materials, the standards used, the difficulties encountered in learning and teaching graphical subjects, the labor market requirements for the level of training of graduates of vocational schools and higher educational institutions. Three questionnaires were prepared for the following target groups:

1. educators, teachers, scientists;

2. students and

3. employers, representatives of the labor market. 56 completed questionnaires were received from employers, 149 from teachers and 349 from students.

To identify the content of the chapters of training materials, in the questionnaire the questions about the topics of technical graphics that are the most difficult for teaching and studying were included. This part of survey was presented by following questions: "What problems of shaping drawings seem 
more difficult to understanding?”, "Which geometrical construction themes seem more difficult to understanding?", "Which projection drawing tasks seem more difficult?", "What seem more difficult in machine drawing creation?", "Which problems seem more difficult in constructional drawing?" Comparing the answers of the first two target groups, it was found that the opinions of students and teachers on this issue coincide. Both teachers and students called the dimensioning in the shaping section the most difficult task for understanding students (38,3\% - teachers, $24,4 \%$ - students), the complicated themes in the mastering of the projection drawing are the creation of cuts $(33,2 \%$ and $32,6 \%$ respectively) and the identification of objects from an orthogonal projection drawing (30,6\% and 26,0\%). For students, the creation of a section (21,3\% and $30,7 \%$ respectively) is also most often mentioned as the more difficult task of this section. In the field of mechanical engineering drawing the topic of assembly drawings $(40,2 \%$ and $32,7 \%)$ is mentioned as causing problems. In the construction drawing section, teachers and students identify drawing in cross section (39,5\% and 34,5\%) as the most difficult task for students.

Answering the question, what difficulties arise in the process of teaching the subject, educators called the main problems are the lack of pre-knowledge (36\%) and interest in studying the subject $(24,8 \%)$ among students, as well as many students in the class (14\%) (Figure 1).

Which difficulties at your work you meet? What kind of active learning methods apply you in the educational process?
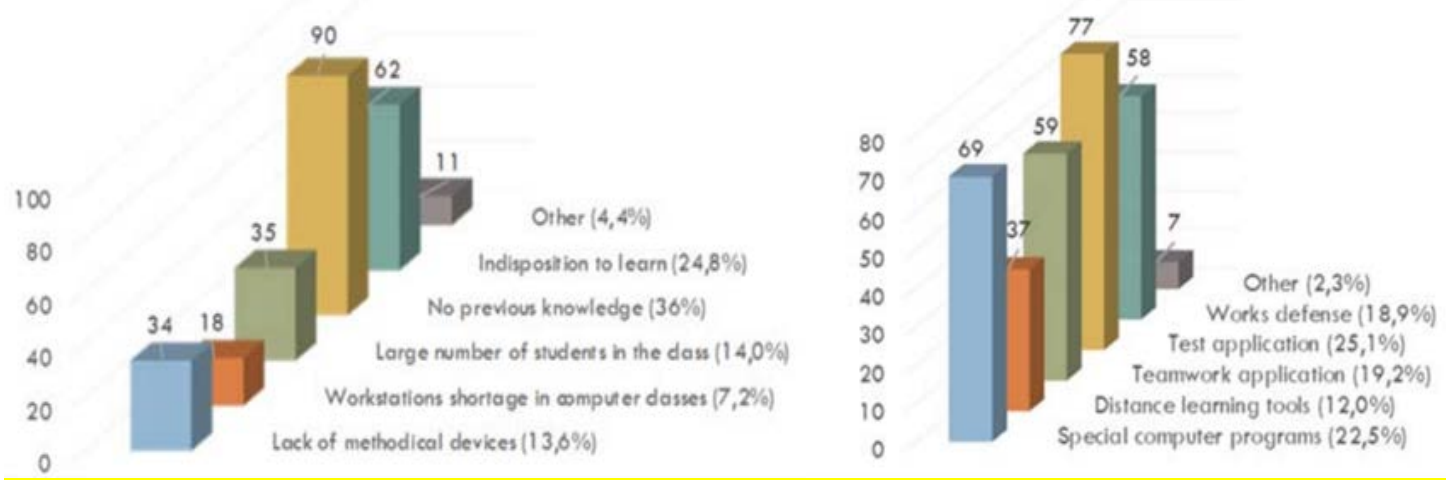

Figure 1 teachers answers on the questions "Which difficulties at your work do you meet?" and "What kind of active learning methods do you apply in education process?"

This confirms the relevance of the project and the need to create video training materials since for Generations $\mathrm{Z}$ the visual form of training is the most effective and able to motivate and promote students' interest in the study. Special computer programs $(22,5 \%)$, applying tests $(25,1 \%)$ and teamwork $(19,2 \%)$ were named as the methods and tools used in the educational process by the largest 
number of educators (Figure 1). This may indicate a lack of training videos in engineering graphical subjects.

Students in their responses noted the importance of engineering graphics in their future careers, and as the main difficulties arising in the study of the subject indicated the lack of prior knowledge and skills needed to create a drawing (Figure2). This indicates the lack of effectiveness of teaching methods of the new generation and the need to create entertaining and interactive teaching tools considering the needs of Generation Z students. Students also expressed a wish to pay more attention to the students, who have never drawn. This need can be met by using video because the student has the opportunity to choose the average rate of information and repetition of training material until sections of the material being learned.

The opinions of teachers and students also coincided on the need to study technical drawing in schools. The results of the survey showed that most teachers and students (78\% of teachers and $63 \%$ of students) suppose that this subject should be compulsory in educational institutions.

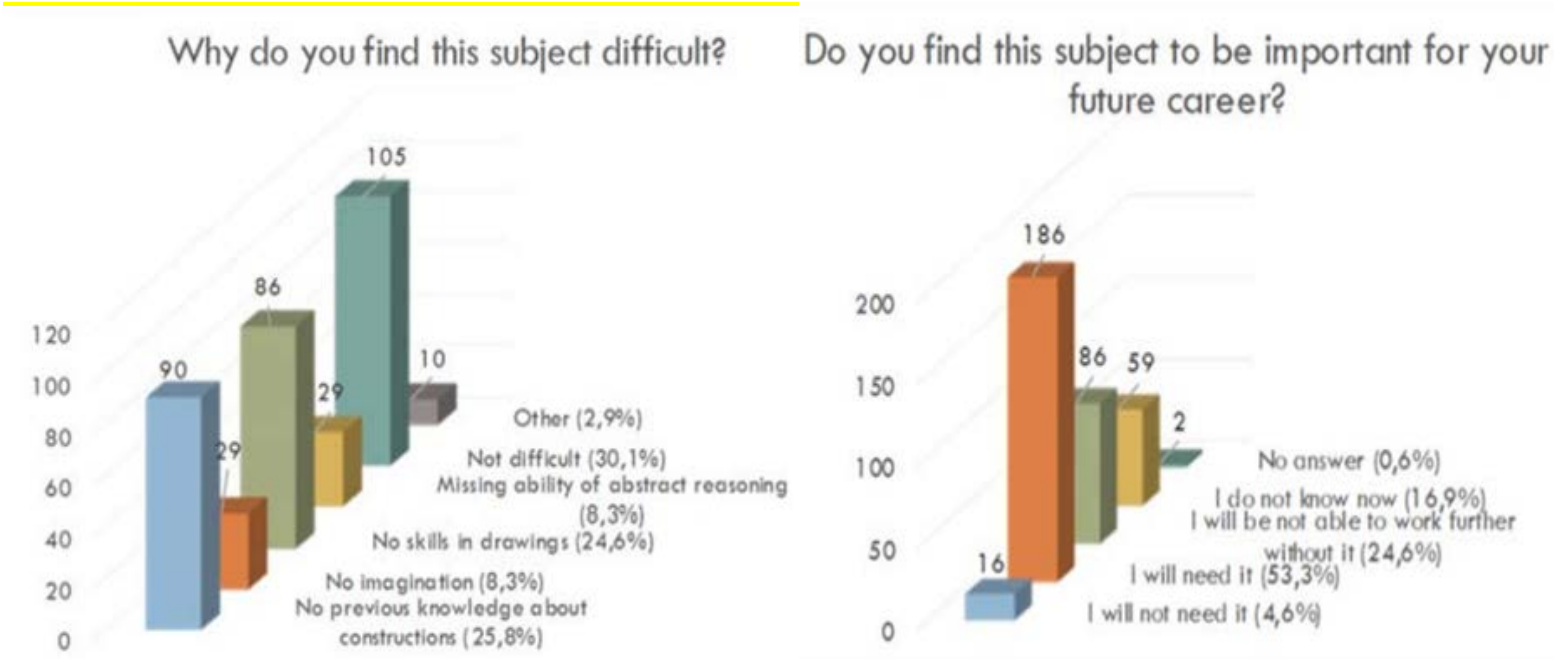

Figure 2 students answers on the questions "Why do you find this subject difficult?" and "Do you find this subject to be important for your future career?"

The average skill level of graduates of vocational schools was evaluated by employers. Knowledge of standards and technical documentation, identification of objects in an orthogonal projection drawing, and understanding of an assembly drawing were rated below average (Figure 3).

According to labour market representatives, graduates of vocational and high schools should have more practical skills, the ability to personalize (configure) CAD systems and be able to use Building Information Modelling software. Graduates also need to have basic knowledge in the field of production technology, tolerances and fit, roughness, machine design, which is necessary for 
the correct design and reading of the list of machine parts. Freehand sketching is a desirable skill in the job market.

How do you rate vocational school graduate's level of preparation in

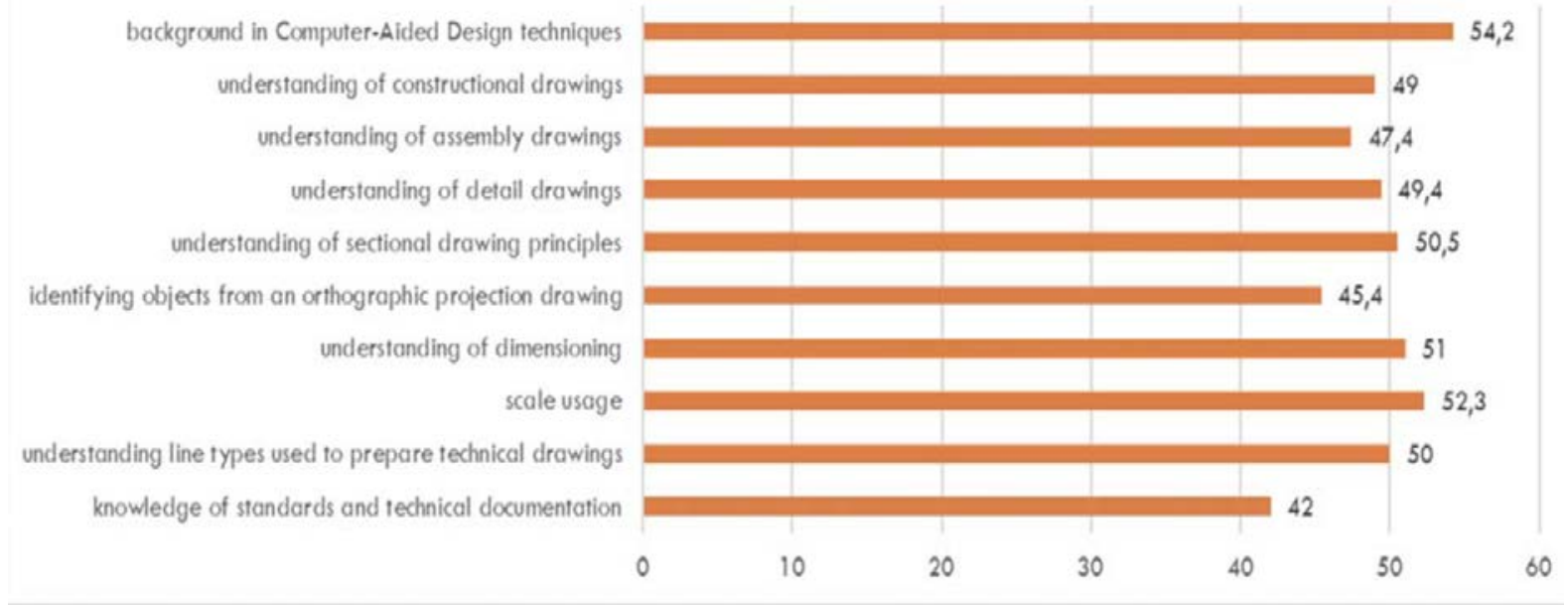

Figure 3 the average level of qualification of vocational school graduates

\section{Interactive and animated drawing teaching tools}

Researchers and teaching staff of the Computer Aided Engineering Graphics Department of RTU were responsible for the creation of the third part of training materials "Joints of parts. Working drawings of parts". In the progress of the project, five training videos were developed. The duration of one teaching material is from 6 to 9 minutes.

The created interactive video materials followed the principles of the cognitive theory of multimedia learning in order to briefly and clearly provide students with information on the topic (Figure4). The cognitive theory of multimedia learning (Meyer \& Moreno, 2005) argues that learning is more effective when words and images are combined to summarize information. This theory defines basic principles of multimedia design:

1. Explanation with words and pictures is better than just words;

2. It is necessary to present words and pictures at the same time, and not separately;

3. To facilitate the processing of visual information for students, it is necessary to limit the visual text to keywords or resumes and present the words as auditory narratives;

4. The principles 1,2 , and 3 work better when students have only limited prior knowledge of content or limited spatial abilities and use only the keywords and essential images to present a coherent summary of information. 


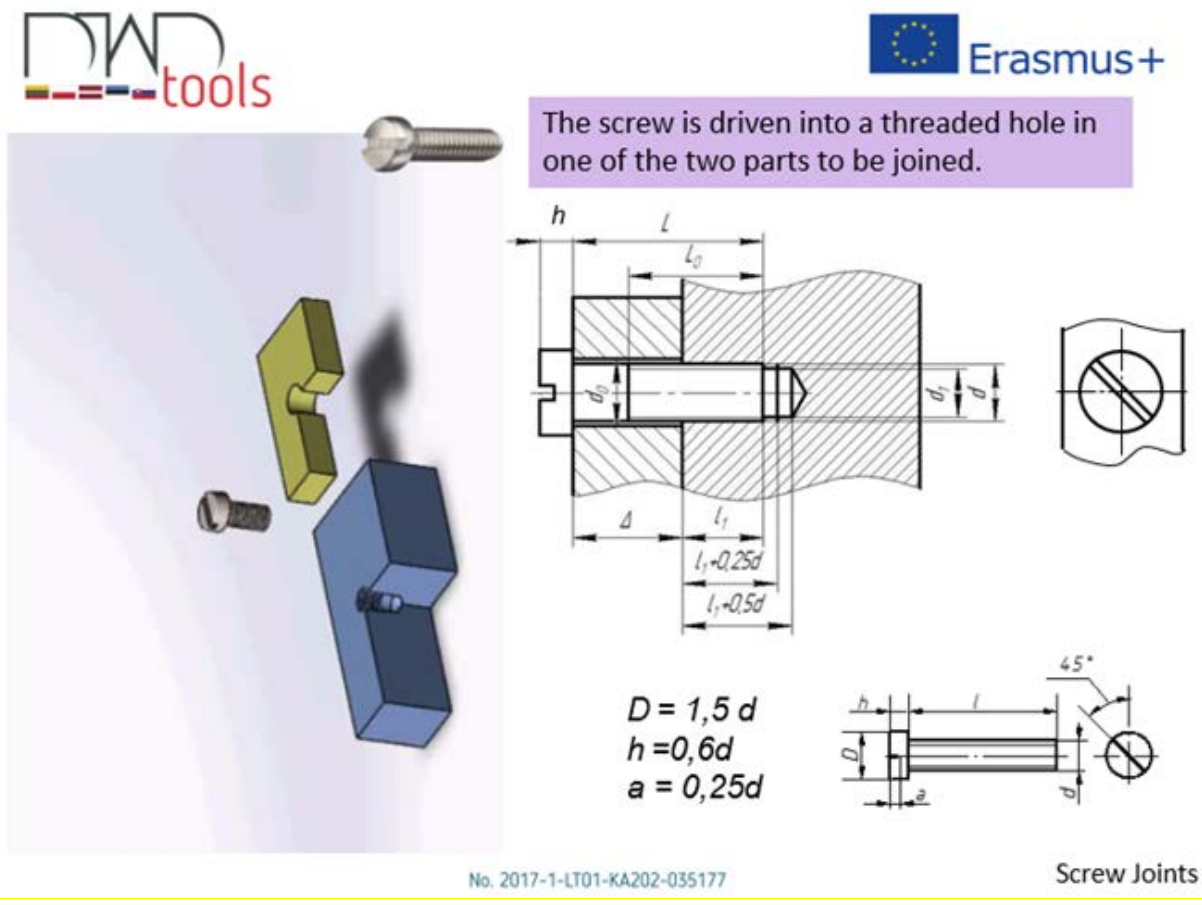

Figure 4 Example of the training video “Threaded Fastenings"

Created video materials can be a component of a learning strategy designed for Z-students and can be used as an additional educational tool to classroom lectures. Educators could demonstrate these learning materials, complementing the topics of their curriculum. Using the created video facilitates the work of the educator, makes it possible to use other teaching methods in the classroom to strengthen or improve learning through other activities. This educational resource is especially necessary when there are a large number of students in the classroom when it is very difficult for the teacher to devote time to each student.

Developed interactive and animated drawing teaching tools consider the characteristics of students. Students will be able to independently study the educational material at a convenient time and at the chosen pace, to study interactive materials as often as they want, until they fully understand it. Watching videos, they may spend more time interacting with content than when attending a lecture. For questions asked to the student in the video material, there is no need to give a quick answer, as it would in a live lecture. Since the interaction between the student and the video takes place in the student's free time, it is possible to ponder the information, check other sources, and then answer the question.

The developed video material can be used in any form of online education (flipped, blended, and fully online) (McGuire \& McGuire, 2015) and for independent study of educational material. In the flipped classroom, the teacher uses the video for extra-curricular activities, but the time in the classroom - to interact with students and solve problems (Bergman \& Sams, 2012). 
SOCIETY. INTEGRATION. EDUCATION

Proceedings of the International Scientific Conference. Volume IV, May $22^{\text {th }}-23^{\text {th }}$, 2020. 681-690

\section{Conclusions}

- $\quad$ The use of video materials is one of the methods of transmitting information using the visual perception of students.

- When developing a video, it is important to keep time limits, so that students stay focused on the training materials.

- $\quad$ Students can receive information quickly and briefly. Students manage to discuss materials and communicate, which allows them to study in a social environment.

- $\quad$ The video courses allow students to watch learning materials at a convenient time and place using smartphones, which allows them to preserve mobility and independence.

- The educational videos have a minimum of text, which allows students to use the videos for independent work and allows lecturers to use them during lectures with additional explanations, comments and remarks.

\section{References}

Bergman, J., \& Sams, A. (2012). Flip your class-room: Reach every student in every class every day. Washington: International Society for Technology in Education (ISTE).

Branoff, T.J., \& Dobelis, M. (2012). The Relationship between Spatial Visualization Ability and Students' Ability to Model 3D Objects from Engineering Assembly Drawings. Engineering Design Graphics Journal of the ASEE, 76(3), 37-43.

Cilliers, E.J. (2017). The challenge of teaching generation Z. PEOPLE: International Journal of Social Sciences, 3(1), 188 - 198.

DOI-https://dx.doi.org/10.20319/pijss.2017.31.188198

Guo, P.J., Kim, J., \& Rubin, R. (2014). How video production affects student engagement: An empirical study of mooc videos. Proceedings of the first ACM conference on Learning@ scale conference, USA, 41-50. DOI:10.1145/2556325.2566239

Jurane, I. (2013). Engineering Education Improvement Opportunities using Computer Games. Society. Integration. Education, 1, 100-109.

Kay, R.H. (2012). Exploring the use of video podcasts in education: A comprehensive review of the literature. Computers in Human Behavior, 28(3), 820-831.

Kim, J., Guo, P.J., Seaton, D.T., Mitros, P., Gajos, K.Z., \& Miller, R.C. (2014). Understanding in-video dropouts and interaction peaks in online lecture videos. Proceedings of the first ACM conference on Learning@ scale conference, USA. 31-40. DOI:10.1145/ 2556325.2566237

Mayer, R.E., \& Moreno, R. (2005). A cognitive theory of multimedia learning: Implications for design principles. Retrieved from http://www.unm.edu/ moreno/PDFS/chi.pdf

McGuire, S.Y., \& McGuire, S. (2015). Teach Students How to Learn: Strategies You Can Incorporate into Any Course to Improve Student Metacognition, Study Skills, and Motivation. VA: Stylus Publishing, LLC. 
Veide \& Strozheva, 2020. Contemporary Needs of Media Learning Materials for Future Z-Engineers

Weinberg, A., \& Thomas, M. (2018). Student Learning and Sense-Making from Video Lectures International Journal of Mathematical Education, 49(9), 1-22. DOI: 10.1080/ 0020739X.2018.1426794 